\title{
Bourgeois Males of the Peacock Blenny, Salaria pavo, Discriminate Female Mimics from Females?
}

\author{
David Gonçalves*, Ricardo Matos†, Teresa Fagundes* \& Rui Oliveira* \\ * Unidade de Investigação em Eco-Etologia, Instituto Superior de Psicologia \\ Aplicada, Lisboa, Portugal; †Department of Animal Behaviour, Zoological \\ Institute, University of Copenhagen, Copenhagen N, Denmark
}

\begin{abstract}
In a Portuguese population of Salaria pavo, two types of reproductively active males occur: large bourgeois males that defend nests and have fully developed secondary sex characters (SSC) and small sneaker males that mimic the females' morphology and behaviour to approach nests and parasitize fertilizations. These two alternative reproductive tactics are sequential, as sneakers develop into bourgeois males. We investigated whether bourgeois males were able to discriminate between sneakers and females of different sizes. In a laboratory experiment bourgeois males were sequentially presented with a female and a sneaker matched for size. Complementary field observations were conducted on the interactions between females and sneakers with bourgeois males. If bourgeois males discriminated females from sneakers, we predicted that they should direct more aggressive behaviours towards sneakers and more courtship acts towards females. In general, bourgeois males courted and attacked small females and sneakers equally. However, large sneakers were courted less and attacked more than large females. Larger sneakers, beginning to develop SSC, were attacked more and courted less by the bourgeois male than smaller sneakers, and larger females were attacked less and courted more than smaller females. These results strongly suggest that only small female-mimicking males were able to deceive bourgeois males. In S. pavo, if the sneakers' fertilization success correlates with their female-mimicking ability, a fitness decrease with an increasing body size can be predicted.

Correspondence: David Gonçalves, Unidade de Investigação em EcoEtologia, ISPA, Rua Jardim do Tabaco 34, 1049-041 Lisboa, Portugal. E-mail: davidg@ispa.pt
\end{abstract}

\section{Introduction}

The occurrence of alternative reproductive tactics (ART) and strategies (see Gross 1996 for a definition of terms) is a widespread phenomenon among fish 
(reviewed in Taborsky 1994, 1999, 2001). In general, small parasitic males cannot compete with larger bourgeois males (sensu Taborsky 1994, 1997) for the access to females or nests. Instead, they try to achieve parasitic fertilizations of eggs by fast spawning rushes or secretive approaches during spawning events between females and bourgeois males.

In a few species the alternative reproductive strategies are fixed for life (e.g. Lepomis macrochirus, Dominey 1980; Gross 1982; Oncorhynchus kisutch, Gross 1985; Xiphophorus nigrensis, Zimmerer \& Kallmann 1989). In the majority of species males first adopt the parasitic tactic, and later, as body size increases, switch to the bourgeois tactic competing for reproductive resources, defending nests and courting females (e.g. Thalasoma bifasciatum, Warner et al. 1975; Neolamprologus brichardi, Taborsky 1985; Pomatoschistus microps, Magnhagen 1992).

In both cases a bimodal distribution of male phenotypes is predicted, with many small males adopting the parasitic tactic and large males adopting the bourgeois tactic, as intermediate-sized males are, in general, less efficient (proposed by Gross 1985 and Taborsky 1999). Bourgeois males benefit from a large body size as they invest in the primary access to females, which often involves the defence of nests or reproductive territories, the development of conspicuous secondary sex characters (SSC) and courtship behaviour, or the development of weapons that increase their fighting potential (Taborsky 1999, 2001).

Adaptations to the parasitic tactic involve an inconspicuous morphology and behaviour in order to approach bourgeois males secretively (Taborsky 1999, 2001), and as a consequence small parasitic males have a higher reproductive success (Gross 1984). In some species sneakers imitate the females' morphology and behaviour in order to approach bourgeois males during spawning events and fertilize eggs (e.g. L. macrochirus, Dominey 1981; Lamprologus callipterus, Sato 1988). If small female-mimicking males are better at deceiving bourgeois males they should also be expected to have a higher reproductive success. Although qualitative observations have suggested that these sneakers are able to deceive bourgeois males (e.g. Gross \& Charnov 1980; Dominey 1981 for L. macrochirus), no experimental tests on the female-mimicking efficiency of these parasitic males have been conducted so far.

In a fish with sequential ART, the peacock blenny, Salaria pavo, small males mimic the females' morphology, courtship behaviour and coloration to try to approach bourgeois males and fertilize eggs during spawning events (Gonçalves et al. 1996). More rarely, sneakers may also try to fertilize eggs by a quick dart into the nest and the same sneaker may display both the streak and the female-mimicking behaviour (D. Gonçalves, pers. obs.). We investigated whether bourgeois males were able to discriminate between parasitic males and females, and whether the efficiency of female mimicry by parasitic males decreased with body size.

Salaria pavo occurs in the intertidal of Mediterranean and Atlantic coasts (Zander 1986). It exhibits a strong sexual dimorphism with males being larger than females, having a well-developed head crest and the first two rays of the anal fin modified into an anal gland (Fishelson 1963; Papaconstantinou 1979; Patzner et al. 1986; Patzner \& Seiwald 1987). Males defend nests in crevices or holes and 
take care of the eggs laid by several females throughout the breeding season (Patzner et al. 1986).

In southern Portugal a population of $S$. pavo occurs in a mudflat area where there is a scarcity of appropriate nest sites. The only hard substrates available for nesting are tiles and bricks used by clam culturists to delimit the frontiers of clam culture fields. Males compete strongly for the access to the few available nest sites and only large males 'qualify to mate' (see Ahnesjö et al. 2001), defending nests and reproducing as bourgeois males (Almada et al. 1994). They avoid leaving the nest to feed or to court females due to the risk of nest takeovers. At the peak of the breeding season almost all nests are covered with eggs and nest space becomes a limiting resource for females. This leads to a biased operational sex ratio towards females and the sex roles are reversed (Almada et al. 1995). Females approach bourgeois males displaying a typical nuptial coloration that consists of the exhibition of alternated dark and light vertical bands, mainly in the head and anterior portion of the body, and court males beating the pectoral fins rapidly with synchronized opercula movements (Almada et al. 1995). Although females play the major role in courtship, males also have the ability to court females. Males jerk the head and anterior portion of the body laterally with intense but low frequency movements while distending the brachiostegal membrane, without leaving the nest (D. Gonçalves, pers. obs.).

Small males are unable to acquire nests and instead act as sneakers. They imitate the females' morphology and courtship coloration and behaviour in order to try to approach bourgeois males and achieve parasitic fertilizations of the eggs (Gonçalves et al. 1996). Sneakers lack or have poorly developed male SSC and have higher gonadosomatic indices than bourgeois males (Gonçalves et al. 1996). The ART are sequential, as sneakers may develop into bourgeois males from one breeding season to the next (D. Gonçalves, T. Fagundes and R. Oliveira, unpubl. data).

In this study, we sequentially presented in a laboratory experiment a bourgeois male with a female and a sneaker matched for size, and measured the agonistic and courtship behaviours displayed by the bourgeois male. Complementary, focal field observations were conducted on sneakers and females, and the behaviours displayed by bourgeois males during interactions with the focal subject were recorded.

If bourgeois males discriminated females from female-mimicking sneakers it was predicted that they should direct more aggressive displays and less courtship acts towards sneakers. As the male ART are sequential, smaller sneakers, with less developed SSC, were predicted to receive less attacks and more courtship acts from the bourgeois males than larger sneakers.

\section{Methods}

\section{Laboratory Experiment}

All animals used in this experiment were collected at Culatra Island in the Ria Formosa Nature Park (Algarve, Southern Portugal) during the species 
breeding season (Jun./Jul.). After capture fish were transported to a field station at the same island, where the experiment took place. The standard length (SL) of all animals was measured and a relative index of head crest development (head height/body height) calculated for sneakers. Males, females and sneakers were kept in three different stock tanks of $80 \times 35 \times 40 \mathrm{~cm}$ provided with shelters in abundance. Only bourgeois males that were defending nests with eggs in the field and ripe females (recognized by a distended belly) were used. Sneakers were identified as such if they lacked or had poorly developed male SSC and if sperm could be easily collected from their vas deferens by gently pressing their abdomen (Gonçalves et al. 1996). Photoperiod was adjusted according to natural conditions. Animals were fed with frozen common cockles and tested $2 \mathrm{~d}$ after capture.

The experimental tank was $50 \times 50 \times 20 \mathrm{~cm}$ and the bottom was covered with a $7 \mathrm{~cm}$ layer of sand. It contained an opaque glass box of $21 \times 5 \times 5.5 \mathrm{~cm}$ with an opening of $2.5 \times 2.5 \mathrm{~cm}$ to be used as a potential nest by males.

Two hours before the experiment a male was inserted in the experimental tank. All males adopted the nest, typically during the first minutes, and spent most of the time with the head extruding from the nest, which is also the most common position adopted in the field.

Each male was sequentially presented with a female and a sneaker on the same day, with an interval of $1 \mathrm{~h}$. Forty-four males were tested (SL: $\overline{\mathrm{x}} \pm \mathrm{SD}=$ $10.2 \pm 1.1 \mathrm{~cm})$. To control for order effects, half of the males were first presented with the female and another half with the sneaker. The female and the sneaker presented to the same male were matched for size, with the female being slightly larger in 17 pairs, the sneaker in 21 pairs and in six pairs fish were the same size (difference in SL, $\overline{\mathrm{x}} \pm \mathrm{SD}=4.0 \pm 2.7 \%, \max =10 \%$, $\min =0 \%$, paired t-test, $\left.\mathrm{t}_{43}=-0.5, \mathrm{p}=0.62, \mathrm{~N}=44\right)$. No fish was used more than once.

The sneaker or female was introduced in the experimental tank and the observation began immediately, lasting $15 \mathrm{~min}$. The observations were video recorded and the behaviours exhibited by the bourgeois male and by the sneaker or female quantified using the Observer PC software V3.0 (Noldus Information Technology, Wageningen, the Netherlands). The behavioural variables recorded for sneakers and females were the frequency and duration of the nuptial coloration and courtship displays and the time spent close to the male (i.e. $10 \mathrm{~cm}$ or less). For males we recorded the frequency of bites and courtship displays performed towards sneakers or females.

No mortality occurred during the experiment and after being used all animals were released in the same place where they had been captured.

\section{Field Observations}

Field observations on the behavioural interactions between nesting males and both sneakers and females were conducted at Culatra Island (Algarve, southern Portugal) during Jun. and Jul. of 1999 and 2000. The study site consisted of a transect with 73 numbered bricks longitudinally aligned along a row of approx. 
$53 \mathrm{~m}$. The gap between adjacent bricks was approx. $30 \mathrm{~cm}$, with a first group of 50 bricks separated from the remaining 23 by $8 \mathrm{~m}$. The bourgeois males defended nests in some of the holes of these bricks.

Every 2 wk all fish found in the transect were captured both during low tide and high tide with a hand net, anaesthetized with MS-222 and individually marked with a combination of coloured plastic beads (diameter $=3 \mathrm{~mm}$ ). The beads were attached to an elastic line that stretches as the fish grows (Floy Tag \& Mfg, Inc., Seattle, Washington, USA). The fish were pierced below the dorsal fin with a fine needle linked to the elastic line and beads, following the procedure described by Patzner (1984). A double knot on the line on the other side of the fish flank prevented the mark from detaching. Subsequently, the SL of all fish was measured and the relative development of the sneakers' head crest was determined as described above. Fish recovered from the anaesthesia in a container with abundant water and aeration and were released in the same place where they had been captured. No mortality occurred during manipulation of animals, and both marked fish kept in tanks and recaptured individuals showed no signs of infections in the pierced area. After the breeding season the tags were removed from all recaptured animals ( $>85 \%)$.

Focal observations were performed by snorkelling during high tide. A total of 21 sneakers and 49 females were observed, and some fish were observed more than once, but always on different days $(\overline{\mathrm{x}} \pm 1 \mathrm{SD}=3.9 \pm 2.8$ for sneakers and $2.8 \pm 2.3$ for females). On the beginning of the observational period a brick number was randomly assigned and the observer would start looking for a marked sneaker or female by swimming in one of the transect directions. After detecting a marked fish an acclimation period of 5 min was given to allow habituation to the observer. After acclimation, focal observations were performed for periods that varied between $20 \mathrm{~min}$ and $1 \mathrm{~h}$. During interactions with a bourgeois male, the number of bites and courtship acts performed by the bourgeois male towards the focal animal, and the number of courtship acts and nuptial coloration displays performed by the focal fish, were recorded on an underwater slate.

As both the duration and the number of observations per fish varied, the interactions among bourgeois males and our focal subjects were used as the unit of comparison. The total number of interactions between bourgeois males and a specific sneaker or female was calculated, and the percentage of those interactions where the focal subject or the bourgeois males displayed a specific behaviour was determined (e.g. if a sneaker interacted 10 times with bourgeois males and was courted twice, a value of $20 \%$ was assigned). Comparisons were subsequently performed on these proportions.

\section{Statistics}

Most of the data did not conform to parametric assumptions and, unless stated otherwise, non-parametric tests were used. Central and dispersion values were given by the median and interquartile range. 
In the laboratory experiment, differences in the behaviour of females and sneakers directed towards the bourgeois male were analysed with Wilcoxon matched pairs tests. As both the frequency and duration of the same behaviours were recorded a Bonferroni correction was applied. In the field, Mann-Whitney U-tests were applied, as females and sneakers visited different males.

The males' behaviour towards females and sneakers of different sizes was predicted to differ. Thus, differences in the frequency of bites and courtship displays performed by bourgeois males towards sneakers and females were analysed with an ANCOVA with the female/sneaker size (SL) being held as a covariate. However, both in the field and in the laboratory the slopes for the relationship between size and the dependent variable were, in all cases, heterogeneous between the female and sneaker treatment, violating a key assumption of this test (e.g. Huitema 1980). In the laboratory experiment and following the procedure suggested by Underwood (1997), the covariate (average size of the female/sneaker pair) was used as a separate factor with two levels ('small' and 'large') in a repeated measures ANOVA. Replicates where the average SL of the female/sneaker pair was below the average of all pairs $(6.04 \mathrm{~cm})$ were included in level 'small' $(\mathrm{n}=22$, size range $=4.65-5.95 \mathrm{~cm})$ and replicates with values above the average were included in level 'large' $(n=22$, size range $=6.05-7.80 \mathrm{~cm}$ ). All variables were log transformed to comply with the homoscedasticity assumption. Some deviations from normality occurred, but ANOVA is considered to be very robust against these deviations (e.g. Box 1953).

Similarly, in the field the proportion of interactions where males directed bites and courtship displays towards females and sneakers was analysed with a two-way ANOVA with sex (sneaker and female) and size ('large' or 'small') as factors. Fish were included in level 'small' if their SL was below the average SL of all females and sneakers observed $(6.4 \mathrm{~cm})$ and in level 'large' if their SL was above this value. Twenty-four females (size range $=4.30-6.30 \mathrm{~cm}$ ) and 17 sneakers (size range $=4.45-6.30 \mathrm{~cm}$ ) were included in level 'small' and 25 females $($ size range $=6.50-10.43 \mathrm{~cm})$ and 4 sneakers $($ size range $=6.50-8.00 \mathrm{~cm})$ in level 'large'. Within-level differences in SL between females and sneakers were not significant ('small' group, $\mathrm{Z}=1.6, \mathrm{p}=0.110$; 'large' group, $\mathrm{Z}=0.9, \mathrm{p}=0.373$ ). Data were square root transformed to comply with the homoscedasticity assumption.

The Spearman rank correlation coefficient was calculated to analyse differences in the behaviours displayed by females and sneakers of different sizes, and in the behaviours displayed by bourgeois males towards sneakers and females of different sizes. As we had predicted that smaller sneakers should receive more courtship acts and less aggressive acts from bourgeois males, correlations between the sneakers' body size and the behaviours displayed by the bourgeois males were one-tailed. All other tests were two-tailed. Analyses of the data were performed with STATisticA v.5.0 A (Statsoft Inc., Tulsa, OK, USA). 


\section{Results}

\section{Laboratory Experiment}

In comparison with sneakers, females exhibited the nuptial coloration more frequently $[\overline{\mathrm{x}}$ (interquartile range): sneakers $=2.0(0.5-4.0)$; females $=4.0(2.0-$ 6.0); Wilcoxon matched pairs test: $\mathrm{Z}=3.0, \mathrm{p}=0.006, \mathrm{~N}=44]$ and for a longer period of time [sneakers $=15.2 \mathrm{~s}(0.6-43.6)$; females $=31.7 \mathrm{~s}(9.1-67.6) ; \mathrm{Z}=2.5$, $\mathrm{p}=0.024, \mathrm{~N}=44]$. Females spent more time courting the bourgeois male [sneakers $=1.4 \mathrm{~s}(0.3-3.6)$; females $=2.9 \mathrm{~s}(0.9-7.3) ; \mathrm{Z}=3.4, \mathrm{p}=0.001, \mathrm{~N}=$ $44]$ and with a higher frequency [sneakers $=2.0(1.0-4.5)$; females $=4.5(2.0-9.0)$; $\mathrm{Z}=3.8, \mathrm{p}<0.001, \mathrm{~N}=44]$, and spent more time close to the bourgeois male [sneakers $=13.3 \mathrm{~s}(8.3-27.3)$; females $=18.6 \mathrm{~s}(13.4-32.3) ; \mathrm{Z}=2.2, \mathrm{p}=0.031$, $\mathrm{N}=44]$.

The behaviours directed by females or sneakers towards the male (i.e. time spent close to the male, time and frequency of courtship acts and time and frequency of nuptial coloration displays) did not correlate with the behaviours displayed by the male (i.e. frequency of bites and courtship acts) towards the presented fish (Spearman's correlation coefficient, $\mathrm{r}_{\mathrm{s}}$, varied between -0.06 and 0.29 for sneakers, $\mathrm{N}=44$, and -0.05 and 0.27 for females, $\mathrm{N}=44$ ), suggesting that the males' behaviour was not significantly influenced by the behaviour of the presented fish.

Large females or sneakers did not behave differently from smaller individuals (Table 1). Differences in the frequency of bites and courtship displays performed by the bourgeois males towards sneakers and females were analysed with a repeated measures ANOVA with the average SL of the female/sneaker pair as a twolevel factor ('small' or 'large' size pair). In all cases the frequency of the males' behaviour towards females and sneakers did not differ $\left(\mathrm{F}_{1,42}<2.7, \mathrm{p}>0.100\right)$. However, a significant interaction between the size of the female/sneaker pair and the sex towards which males directed their behaviours (sneaker or female)

Table 1: Spearman's rank correlation coefficients between the standard lengths of females and sneakers and the behaviours displayed towards bourgeois males, both in the laboratory experiment and in the field

\begin{tabular}{|c|c|c|c|c|c|c|c|c|}
\hline & \multicolumn{4}{|c|}{ Laboratory experiment } & \multicolumn{4}{|c|}{ Field observations } \\
\hline & \multicolumn{2}{|c|}{$\begin{array}{l}\text { Sneakers } \\
(\mathrm{N}=44)\end{array}$} & \multicolumn{2}{|c|}{$\begin{array}{l}\text { Females } \\
(\mathrm{N}=44)\end{array}$} & \multicolumn{2}{|c|}{$\begin{array}{l}\text { Sneakers } \\
(\mathrm{N}=21)\end{array}$} & \multicolumn{2}{|c|}{$\begin{array}{l}\text { Females } \\
(\mathrm{N}=49)\end{array}$} \\
\hline & $\mathrm{r}_{\mathrm{s}}$ & $\mathrm{p}$ & $r_{s}$ & $\mathrm{p}$ & $r_{s}$ & $\mathrm{p}$ & $r_{s}$ & $\mathrm{p}$ \\
\hline Nuptial coloration frequency & 0.05 & 0.76 & 0.07 & 0.64 & 0 & 0.97 & 0.03 & 0.88 \\
\hline Nuptial coloration duration ${ }^{\mathrm{a}}$ & 0.05 & 0.72 & 0.05 & 0.73 & & & & \\
\hline Courtship acts frequency & 0 & 0.96 & 0.02 & 0.88 & 0.05 & 0.81 & -0.02 & 0.9 \\
\hline Courtship acts duration ${ }^{\mathrm{a}}$ & 0 & 0.50 & -0.04 & 0.78 & & & & \\
\hline Time close to male $\mathrm{a}^{\mathrm{a}}$ & 0.11 & 0.5 & -0.13 & 0.41 & & & & \\
\hline
\end{tabular}

${ }^{\mathrm{a}}$ Not measured during field observations. 
occurred in all cases $\left(\mathrm{F}_{1,42}>5.0, \mathrm{p}<0.030\right)$, suggesting differences in the males' behaviour towards sneakers and females of different sizes. Indeed, Tukey post-hoc HSD tests revealed that in the 'large' size group sneakers received more bites ( $\mathrm{p}=$ $0.020)$ but were not courted less often than females $(p=0.202)$ (Table 2$)$, while in the 'small' size group no differences occurred for the frequency of courtship displays $(\mathrm{p}>0.651)$, although females received more bites than sneakers $(\mathrm{p}<0.001)$ (Table 2).

Larger sneakers had more developed head crests $\left(\mathrm{r}_{\mathrm{s}}=0.5, \mathrm{p}=0.001, \mathrm{~N}=\right.$ $44)$ and they received more bites $\left(\mathrm{r}_{\mathrm{s}}=0.5, \mathrm{p}<0.001, \mathrm{~N}=44\right.$, Fig. 1) and were courted less often by the bourgeois males $\left(\mathrm{r}_{\mathrm{s}}=-0.4, \mathrm{p}=0.006, \mathrm{~N}=44\right)$ than smaller sneakers. In contrast, larger females received less bites $\left(r_{\mathrm{s}}=-0.4, \mathrm{p}=\right.$ $0.018, \mathrm{~N}=44$, Fig. 1$)$ and were courted more often $\left(\mathrm{r}_{\mathrm{s}}=0.3, \mathrm{p}=0.034, \mathrm{~N}=44\right)$ than smaller females.

\section{Field Observations}

Females displayed the nuptial coloration and courted the bourgeois male in a higher proportion of interactions than sneakers (nuptial coloration, sneakers: $60.0 \pm 7.3 \%, \mathrm{~N}=21$; females: $88.9 \pm 4.2 \%, \mathrm{~N}=49$; Mann-Whitney U-test: $\mathrm{Z}=2.0, \mathrm{p}=0.040$; courtship acts, sneakers: $66.7 \pm 7.5 \%, \mathrm{~N}=21$; females: $100.0 \pm 3.9 \%, \mathrm{~N}=49 ; \mathrm{Z}=2.4, \mathrm{p}=0.018)$.

The proportion of interactions where females or sneakers displayed courtship behaviour or nuptial coloration did not correlate with size (Table 1).

A two-way ANOvA with sex (female or sneaker) and body size ('large' or 'small') as factors was applied to test whether the proportion of interactions where males courted and attacked sneakers and females of different sizes differed. Bourgeois males directed bites in a higher proportion of interactions towards sneakers (bites: $\mathrm{F}_{1,66}=18.8, \mathrm{p}<0.001$ ) and courtship displays in a higher proportion of interactions towards females $\left(\mathrm{F}_{1,66}=11.3, \mathrm{p}<0.001\right)$. A significant interaction between the two factors, size and sex, occurred for both variables $\left(\mathrm{F}_{1,66}>11.2, \mathrm{p}<0.001\right)$, once again suggesting differences in the males' behaviour towards females and sneakers of different sizes. Post-hoc unequal $\mathrm{N}$ Tukey HSD tests revealed that no differences occurred in the proportion of interactions where males performed bites and courtship displays towards females and sneakers in the 'small' size group ( $\mathrm{p}>0.594)$. In the 'large' size group males bit $(\mathrm{p}<0.001)$ sneakers in a higher proportion of interactions, and courted sneakers in a lower proportion of interactions $(\mathrm{p}=0.021)$ (Table 2).

Again, larger sneakers had more developed head crests $\left(\mathrm{r}_{\mathrm{s}}=0.6, \mathrm{p}=0.002\right.$, $\mathrm{N}=21)$ and were attacked $\left(\mathrm{r}_{\mathrm{s}}=0.5, \mathrm{p}=0.014, \mathrm{~N}=21\right)$ in a higher proportion of interactions with bourgeois males in comparison with smaller sneakers, although they were courted in a similar proportion of interactions $\left(r_{s}=-0.2\right.$, $\mathrm{p}=0.190, \mathrm{~N}=21)$.

In contrast, larger females were attacked $\left(\mathrm{r}_{\mathrm{s}}=-0.6, \mathrm{p}<0.001, \mathrm{~N}=49\right)$ in a lower proportion of interactions with bourgeois males than smaller females, and courted in a higher proportion of interactions $\left(r_{s}=0.6, p<0.001, N=49\right)$. 


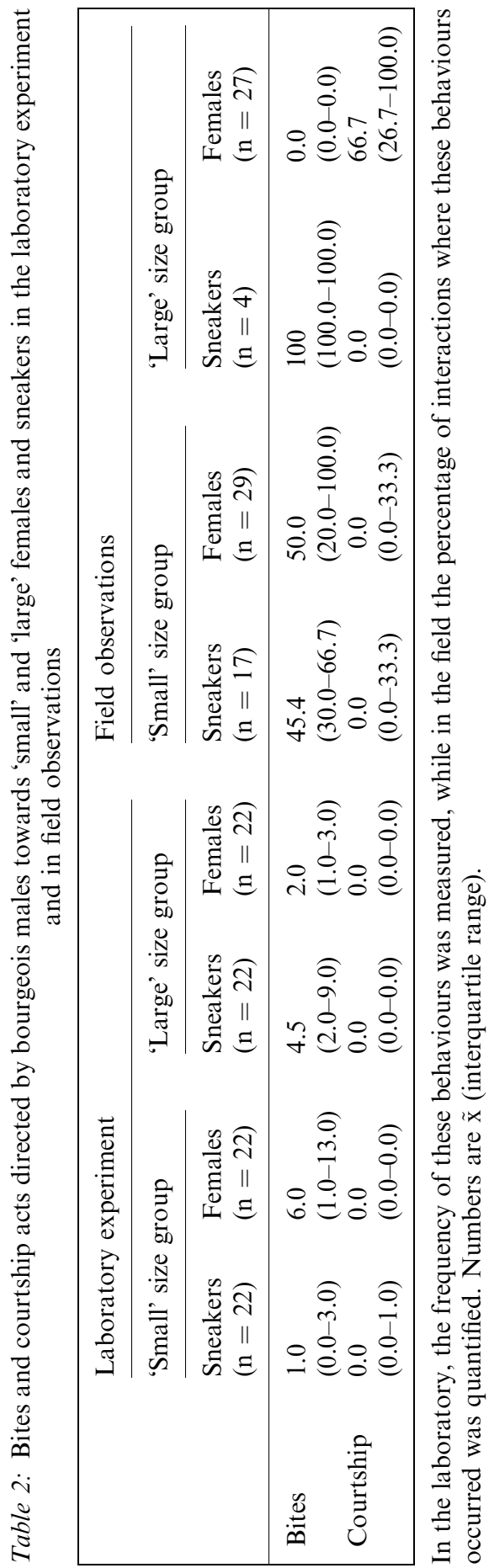


(a)
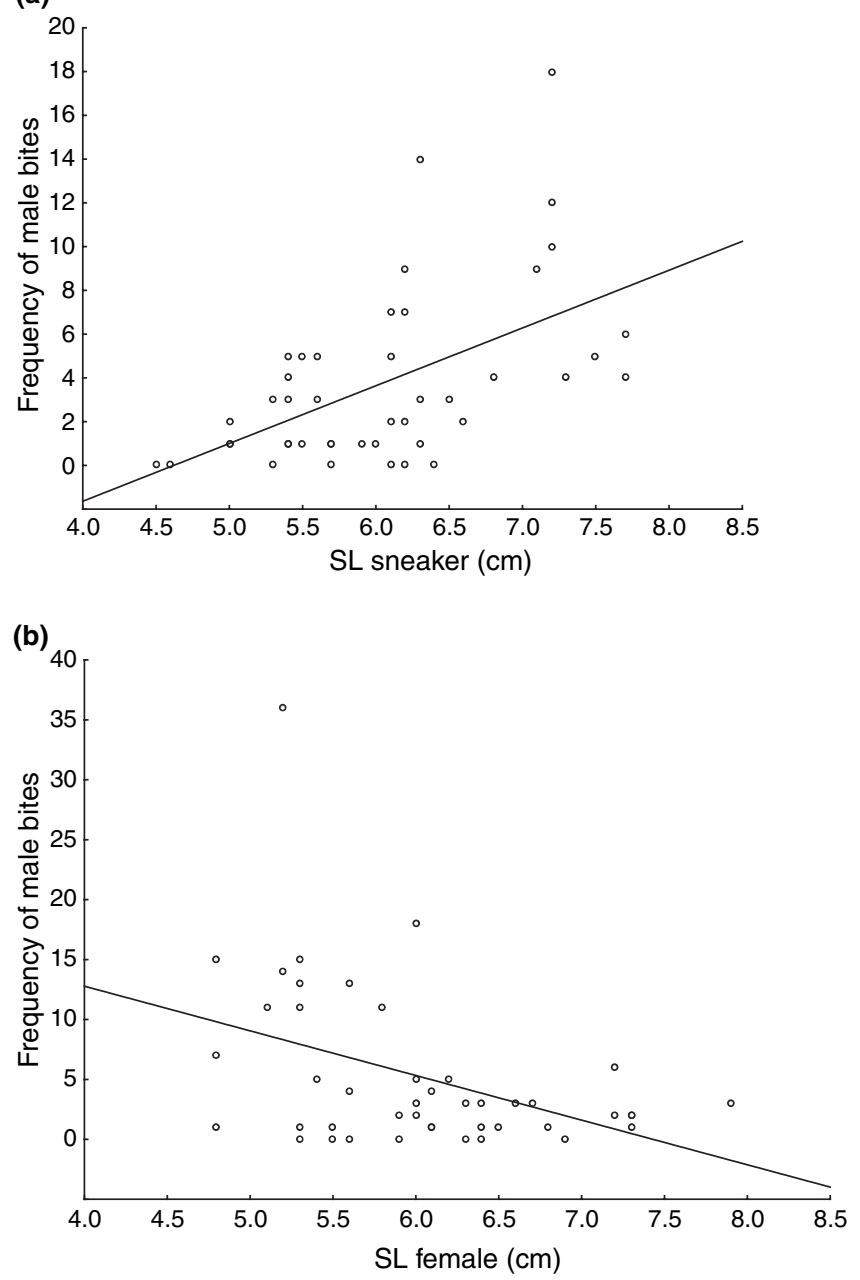

Fig. 1: Frequency of male attacks towards sneakers (a) and females (b) of different sizes during the laboratory experiment

\section{Discussion}

In general, in the 'small' size group the frequency of agonistic and courtship behaviours directed by bourgeois males towards females and sneakers did not differ. Contrarily, in the 'large' size group sneakers received more agonistic acts and less courtship displays than females. As sneakers' body size increased, there was also an increase in the frequency of agonistic acts and a decrease in the frequency of courtship displays performed by the bourgeois males. The opposite was true for females, with larger females being more courted and less attacked. These results strongly suggest that: 
1. bourgeois males were deceived by small sneakers and could not discriminate them from small females. Although female mimicry has been reported for more than 30 species (Taborsky 1998), to our knowledge this is the first experimental demonstration that female-mimicking males are able to deceive bourgeois males. This fact is even more surprising if we consider the marked sexual dimorphism in $S$. pavo and the reversal of sex roles in the studied population, with females displaying an elaborate courtship behaviour and coloration. Small sneaker males were thus able to mimic the females' morphology in spite of the strong sexual dimorphism and to successfully imitate the complex female sexual displays;

2. bourgeois males were able to discriminate large females from large sneakers.

Although a decrease in the success of parasitic males with increasing body size is easy to understand for parasitic males relying on cryptic tactics to fertilize eggs as a larger body size should facilitate detection by bourgeois males, for species like $S$. pavo where parasitic males rely on female mimicking to approach nests, the situation is less clear. In $S$. pavo females as large as $12.3 \mathrm{~cm}$ (total length) occur in the study area and many reproductive bourgeois males are smaller than this (Almada et al. 1994; Gonçalves et al., unpubl. data). Thus, sneakers could theoretically switch to the bourgeois tactic with a very short nonreproductive transitional period. However, sneakers start to develop SSC (crest and anal gland) between 6 and $8 \mathrm{~cm}$, and bourgeois males of this size are extremely rare in the population (Gonçalves et al., unpubl. data). From a bourgeois male point of view, discrimination of small differences between sneakers and females may be more difficult in smaller individuals and an increase in target areas might facilitate discrimination. This would explain why larger sneakers were more often attacked which, in turn, could be the social signal triggering the physiological mechanisms leading to the tactic change, explaining why large sneakers start to develop male SSC and decrease gonadal investment (Oliveira et al. 2001).

A selective pressure on bourgeois males to mate preferentially with large females can be expected, not only because of their higher fecundity and larger eggs (as demonstrated for many fish species, e.g. the redlip blenny, Ophioblennius atlanticus, Côte \& Hunte 1989), but also to reduce the risk of parasitic fertilizations of eggs, as large parasitic males are recognized more easily. Accordingly, in a previous study it was already demonstrated that bourgeois males of this species prefer to mate with larger females (Gonçalves \& Oliveira 2003). In the studied population the operational sex ratio seems to be highly biased in the direction of females and as a consequence the costs for bourgeois males of rejecting small females may be presumably low if large females are available for mating.

Intersexual conflicts can also be predicted between females and sneakers. In the 13 species of teleosts that have been tested to date, females always preferred to mate with the bourgeois male rather than with sneakers (Taborsky 1994, 1999). Likewise, females of $S$. pavo were rarely observed to court parasitic males, and the 
courted ones were already beginning to develop SSC (D. Gonçalves, pers. obs.). Although the sex roles are reversed in this population, females have also been shown to select males (e.g. males with larger crests were preferred by females in a laboratory experiment, Gonçalves \& Oliveira 2003). If females of $S$. pavo are also unable to discriminate small sneakers from other females (which still remains to be tested) and prefer to spawn in nests without sneakers (as demonstrated for many other species with ART, e.g. Symphodus ocellatus van den Berghe et al. 1989, but see Candolin \& Reynolds 2002) intersexual conflicts may arise; females should prefer to spawn in nests without any small conspecifics in their vicinity as some of these may be sneakers. However, females also prefer to spawn in nests that have more, and more recent eggs (T. Fagundes, D. Gonçalves \& R. Oliveira, unpubl. data) and these nests have, on average, more females and sneakers associated with them (Gonçalves et al. 2003). This situation is similar to the one described for $S$. ocellatus where both females and sneakers prefer nests that had recently received eggs (Alonzo \& Warner 1999), although females avoid to spawn in nests with sneakers (van den Berghe et al. 1989; Alonzo \& Warner 1999).

Thus, in $S$. pavo the dynamics of the intra- and intersexual interactions are apparently more complex than in many other species, as sneakers mimic females and as the mimicking ability of sneakers depends on their body size. Future experimental work and a dynamic model of the species reproductive system may clarify the factors determining the mating system of this sex role reversed population of $S$. pavo.

In conclusion, small sneakers of $S$. pavo seem to be efficient female mimics to the eyes of bourgeois males. This is unlikely to relate to the fact that this is a sex role reversed population. Bourgeois males displaying traditional roles from other $S$. pavo populations or from other species should also benefit from discriminating females from sneakers and the same intersexual conflicts between female mimics and females are expected, with female mimics being selected to increase their mimicking abilities and females being selected to diverge from female mimics. Future experiments similar to the one presented here should be applied to other species with ART, sex role reversed or with traditional sex roles, for a better understanding of the importance of intra- and intersexual conflicts on the evolution of ART.

\section{Acknowledgements}

We are grateful to the Ria Formosa Nature Park for providing essential logistical support. During this study DMG was funded by a PRAXIS XXI PhD grant (BD/13436/97). The Portuguese Science and Technology Foundation supported this study (UI\&D331/94).

\section{Literature Cited}

Ahnesjö, I., Kvarnemo, C. \& Merilaita, S. 2001: Using potential reproductive rates to predict mating competition among individuals qualified to mate. Behav. Ecol. 12, 397-401. 
Almada, V. C., Gonçalves, E. J., Santos, A. J. \& Baptista, C. 1994: Breeding ecology and nest aggregations in a population of Salaria pavo (Pisces: Blenniidae) in an area where nest sites are very scarce. J. Fish Biol. 45, 819-830.

Almada, V. C., Gonçalves, E. J., Oliveira, R. F. \& Santos, A. J. 1995: Courting females: ecological constraints affect sex roles in a natural population of the blenniid fish, Salaria pavo. Anim. Behav. 49, $1125-1127$.

Alonzo, S. H. \& Warner, R. R. 1999: Dynamic games and field experiments examining intra- and intersexual conflict: explaining counterintuitive mating behavior in a Mediterranean wrasse, Symphodus ocellatus. Behav. Ecol. 11, 56-70.

van den Berghe, E. P., Wernerus, F. \& Warner, R. R. 1989: Female choice and the cost of peripheral males. Anim. Behav. 38, 875-884.

Box, G. E. P. 1953: Non-normality and tests on variances. Biometrika 40, 318 - 335.

Candolin, U. \& Reynolds, J. D. 2002: Why do males tolerate sneakers? Tests with the European bitterling, Rhodeus sericeus. Behav. Ecol. Sociobiol. 51, 146-152.

Côte, I. \& Hunte, W. 1989: Male and female mate choice in the redlip blenny Ophioblennius atlanticus: why bigger is better. Anim. Behav. 38, 78-88.

Dominey, W. J. 1980: Female mimicry in male bluegill sunfish - a genetic polymorphism? Nature 284, $546-548$.

Dominey, W. J. 1981: Maintenance of female mimicry as a reproductive strategy in bluegill sunfish (Lepomis macrochrirus). Environ. Biol. Fishes 6, 59-64.

Fishelson, L. 1963: Observations on littoral fishes of Israel. I. Behaviour of Blennius pavo Risso (Teleostei: Blenniidae). Isr. J. Zool. 12, 67-80.

Gonçalves, D. \& Oliveira, R. F. 2003: Time spent close to a sexual partner as a measure of female mate-preference in a sex-role reversed population of the blenny Salaria pavo (Pisces: Blenniidae). Acta Ethol. 6, 1-5.

Gonçalves, E. J., Almada, V. C., Oliveira, R. F. \& Santos, A. J. 1996: Female mimicry as a mating tactic in males of the blenniid fish Salaria pavo. J. Mar. Biol. Assoc. U.K. 76, 529-538.

Gonçalves, D., Fagundes, T. \& Oliveira, R. 2003: Reproductive behaviour of sneaker males of the peacock blenny. J. Fish Biol. 63, 528-532.

Gross, M. R. 1982: Sneakers, satellites and parentals: polymorphic mating strategies in North American sunfishes. Z. Tierpsychol. 60, 1-26.

Gross, M. R. 1984: Sunfish, salmon, and the evolution of alternative reproductive strategies and tactics in fishes. In: Fish Reproduction: Strategies and Tactics (Wootton, R. J. \& Potts, G., eds). Academic Press, London, pp. 55-75.

Gross, M. R. 1985: Disruptive selection for alternative life histories in salmon. Nature 313, 47-48.

Gross, M. R. 1996: Alternative reproductive strategies and tactics: diversity within sexes. Trends Ecol. Evol. 11, 92-98.

Gross, M. R. \& Charnov, E. L. 1980: Alternative male life histories in bluegill sunfish. Proc. Nat. Acad. Sci. U.S.A. 77, 6937-6940.

Huitema, B. E. 1980: The Analysis of Covariance and Alternatives. Wiley Interscience, New York.

Magnhagen, C. 1992: Alternative reproductive behaviour in the common goby, Pomatoschistus microps: an ontogenetic gradient? Anim. Behav. 44, 182-184.

Oliveira, R. F., Gonçalves, E. J. \& Santos, R. S. 2001: Gonadal investment of young males in two blenniid fishes with alternative reproductive tactics. J. Fish Biol. 59, 459-462.

Papaconstantinou, C. A. 1979: Secondary sex characters of Blennioid fishes (Pisces: Blenniidae). Thalassographica 1, 57-75.

Patzner, R. A. 1984: Individual tagging of small fish. Aquaculture 40, 251-253.

Patzner, R. A. \& Seiwald, M. 1987: The reproduction of Blennius pavo. II. Secondary sexual organs and accessory glands of the testis during the reproductive cycle. In: Proceedings of the V Congress of European Ichthyologists (Kullander, S. \& Fernholm, B., eds). Swedish Museum of Natural History, Stockholm, pp. 293-298.

Patzner, R. A., Seiwald, M., Adlgasser, M. \& Kaurin, G. 1986: The reproduction of Blennius pavo. V. Reproductive behaviour in natural environment. Zool. Anz. 216, 338-350.

Sato, T. 1988: Mating systems and parental care of a shell brooder, Lamprologus callipterus. In: Ecological and Limnological Study on Lake Tanganyika and its Adjacent Regions (Kawanabe, H. \& Kwetuenda, M. K., eds). Kyoto Univ. Press, Kyoto, pp. 23-24. 
Taborsky, M. 1985: Breeder-helper conflict in a cichlid fish with broodcare helpers - an experimental analysis. Behaviour 95, 45-75.

Taborsky, M. 1994: Sneakers, satellites and helpers: parasitic and cooperative behaviour in fish reproduction. Adv. Study Behav. 23, $1-100$.

Taborsky, M. 1997: Bourgeois and parasitic tactics: do we need collective, functional terms for alternative reproductive behaviors? Behav. Ecol. Sociobiol. 41, 361-362.

Taborsky, M. 1998: Sperm competition in fish: 'bourgeois' males and parasitic spawning. Trends Ecol. Evol. 13, 222-227.

Taborsky, M. 1999: Conflict or cooperation? What determines optimal solutions to competition in fish reproduction? In: Behaviour and Conservation of Littoral Fishes (Almada, V. C., Oliveira, R. F. \& Gonçalves, E. J., eds). ISPA, Lisboa, pp. 301-349.

Taborsky, M. 2001: The evolution of bourgeois, parasitic, and cooperative reproductive behaviors in fishes. J. Hered. 92, 100-110.

Underwood, A. J. 1997: Experiments in Ecology: Their Logical Design and Interpretation Using Analysis of Variance. Cambridge Univ. Press, Cambridge.

Warner, R. R., Robertson, D. R. \& Leigh, E. G. Jr 1975: Sex change and sexual selection. Science 190, 633-638.

Zander, C. D. 1986: Blenniidae. In: Fishes on the North-Eastern Atlantic and the Mediterranean (Whithead, P. J. P., Bauchot, M. L., Hureau, J. C., Nielsen, J. \& Tortonese, E., eds). UNESCO, Paris, pp. 1096-1112.

Zimmerer, E. J. \& Kallmann, K. D. 1989: The genetic basis for alternative reproductive tactics in the pigmy swordtail, Xyphophorus nigrensis. Evolution 43, 1298-1307.

Received: May 19, 2004

Initial acceptance: July 27, 2004

Final acceptance: November 24, 2004 (M. Taborsky) 